Vietnam Journal of Mechanics, VAST, Vol.30, No.2 (2008), pp. 89 -98

\title{
EXPERIMENTAL RESULTS OF GASLIFT PROCESS
}

\author{
Duong Ngoc Hai \\ Institute of Mechanics, VAST \\ Nguyen Duy Thien \\ Electric Power University, \\ Nguyen Van Canh \\ Oil-Gas Joint Venture Vietsovpetro
}

\begin{abstract}
In the paper, the investigation results of periodical gas-lift flows in vertical pipes using experiment method are presented. The experiment facilities consist of flow measurement equipment, gas and fluid supplier facilities, tubing system. To study the influence of medium physical and dynamical characteristics on the process efficiency, two liquid-gas systems are used, namely, water-air and spindle oil-air. The objects of investigation are to obtain data from tests conducted in some conduits and to analyse the influence of system physical, geometrical and etc. parameters such as: initial liquid height in the conduits, gas injected volume, conduit diameter, conduit configuration and etc. on the considered process.
\end{abstract}

Key words: conduit; two phase gas-liquid mixtures; liquid slug, periodical gas-lift.

\section{INTRODUCTION}

A big part of crude oil wells in the world is being produced using gas-lift techniques (see $[2,3,6,9])$. Gas lift, known as continuous and periodical (intermittent) lift, is realized by injection of high pressure gas in well, in order to create the necessary flowing bottom hole pressure to produce the desired rate of crude oil. Continuous gas-lift is accomplished by constant gas injection in order to create the rising hydrocarbon stream. As the reservoir depletes, reservoir pressure reaches the value at which continuous gas injection does not efficiently lift liquids to the surface and the better option is periodical injections. Very little works has been published on the topics. Brill et al. (1967) reported the results of wide range of intermittent gas-lift tests conducted in 31.3-38.1 mm diameter experimental wells. Neely et al. (1974) conducted field test and correlated the average gas velocity below the liquid slug with liquid holdup predicted from continuous flow correlations. Schmidt et al. (1984) presented dynamic model for three-stage gas-lift cycle. The theoretical works related to different aspects of considered process can be seen, for example, in $[3,4,5,11$, 12 .

In this paper, the investigation results of upward flows of periodical gas-lift using experiment method are presented. The experiment facilities consist of flow measurement equipment, gas and fluid supplier facilities, tubing system. To study the influence of medium physical and dynamical characteristics on the process efficiency, two gas-liquid systems are used: water-air and spindle oil No.10-air. The objects of investigation are to obtain data from tests conducted in some conduits and to analyse the sensitivity of system parameters such as: physical, geometrical and etc. parameters. The obtained results show that besides 
gas injected volume the medium characteristics and tubing geometry are main parameters which influence on the considered process. Using enlargement tubing-chamber leads to higher process efficiency. The optimal regime exists with gas-liquid ratio minimum.

\section{EXPERIMENT}

\subsection{Principal working scheme of oil production well using periodical gas lift technique}

In Fig. 1 the principal working scheme of the oil production well using periodical gas lift technique and technology is presented. The main components of well are the small diameter conduit for oil lift, outside the bigger conduit for protection and high pressure gas reservation. The gas lift valve is installed in the low possible place of the lift conduit and near the well bottom. There are different sort of gas lift valve, for example, differential valve, pilot operated gas lift valve and etc. When the pressure in the annular between two conduits reaches the initially determined values, the valve will work (be opened or closed). As presented in Fig. 1, the process of periodical liquid lift using gas consists of 4 phases: Phase 1: The oil from reservoir flows into and reserves in the lift conduit and, in the same time, gas will flow into and be reserved in annular between two conduits served as gas tank; Phase 2: The gas pressure is high enough and the gas lift valve is opened, gas flows into the lift conduit, creates the gas bubble and push liquid (oil) to move upwards; Phase 3: Oil reaches the out end (surface) of lift conduit and runs into transport horizontal pipelines; and Phase 4: The gas lift valve is closed, liquid film and drops fall back downwards in lift conduit and Phase 1 begins again.

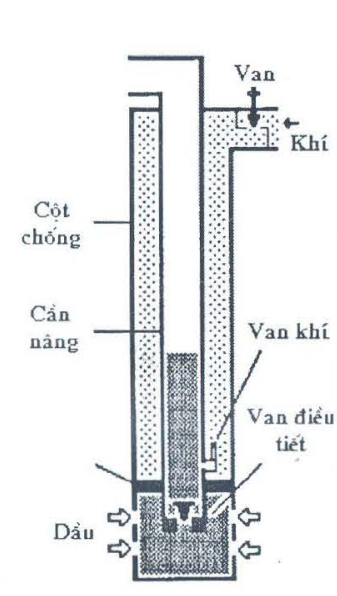

a)

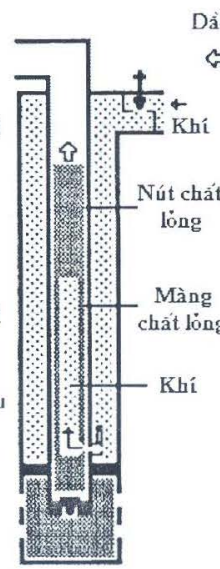

b)

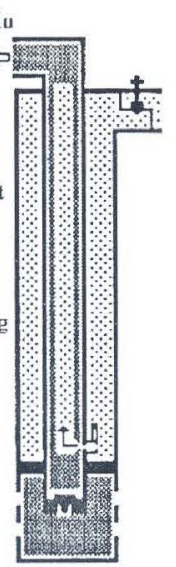

c)

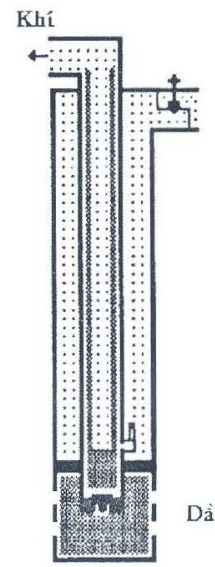

d)

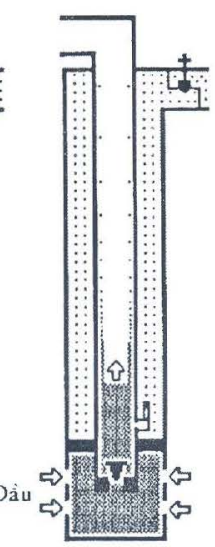

e)

Fig. 1. Principal working scheme of oil production well using periodical gas lift technique

\subsection{Scheme of experimental facilities}

In Fig. 2 the schematic diagram of the experimental facilities for periodical gas lift tests is presented. In the experiments, two liquid-gas systems are used, namely, water-air and spindle oil No.10-air. The lift conduits are made by plastic tubes of inner diameters $d=18 ; 24$ and $30.8 \mathrm{~mm}$. The height of experimental lift conduit $H$ is $16 \mathrm{~m}$. That means 
the maximum calibrated (or nominated) length of conduits $H_{C}=H / d$ is $\sim 900$. The conduit can be vertical installed $(\phi=0)$ or inclined with inclination angle $\phi$ of $7^{0}$ or $14^{0}$. The initial liquid accumulated in the lift conduit height $H_{L}$ can be changed: $H_{L}=5 \div 8$ $\mathrm{m}$. In experiments, instead of annular, the gas tank with constant pressure is used: $p_{G}=$ constant.

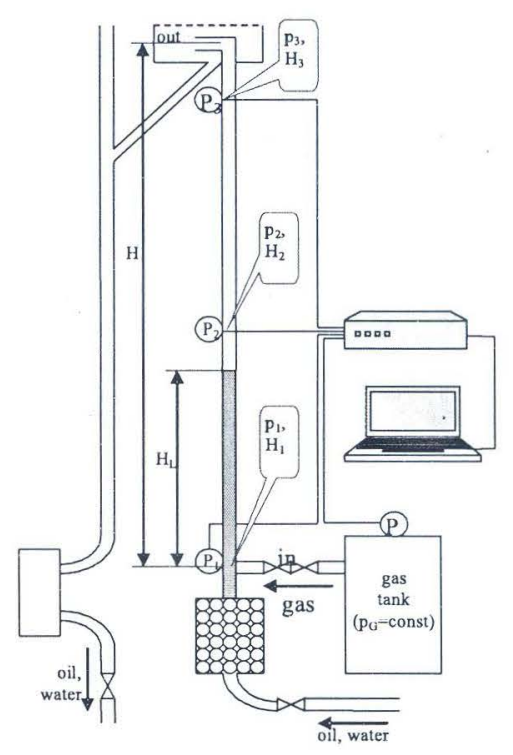

Fig. 2. Schematic diagram of experimental setup

When the liquid accumulated in conduits reaches the determined height, gas lift valve installed in the low end of conduit is opened and gas flows into lift tube. The gas occupies the volume and pushes liquid to move upwards. During upwards moving, gas partly penetrates into liquid and part of liquid slug falls back. Meanwhile a big part of liquid reaches the surface (the out end of conduit) and runs into tank. The liquid volume reached the surface represents the efficiency of lift process. This volume will depend on many parameters such as initial liquid height in conduit, liquid and gas properties, gas injected volume, conduit configuration and etc. To manage the gas injected volume we can regulate in two ways through the valve open time and the gas injection velocity (or gas tank pressure $p_{G}$ ). The measurement data such as gas, liquid pressure, slug moving velocity, gas injected volume, etc. depended on time are gathered and saved using sensors, data acquisition equipment and $\mathrm{PC}$.

\subsection{Experimental results, analysis and discussion}

In Fig. 3 the pressure curves for 3 points $P_{1}, P_{2}$ and $P_{3}$ (at places $H_{1}=0 \mathrm{~m}, H_{2}=8 \mathrm{~m}$, and $H_{3}=15.6 \mathrm{~m}$ from valve installed place) along the lift conduit are presented. Analysing these curves we can determine the flow pattern change moments: the opened or closed moments of gas lift valve, the moment of liquid slug moving through the measurement points and the finished moments of phases. According to Fig. 3 during Phase 2, the gas pressure is higher than initial liquid pressure at conduit bottom. During this phase the pressure difference $\Delta \mathrm{p}$ is determined mainly by liquid hydrostatic pressure, gas pressure 
and valve structure: $\Delta p=k\left(p_{G}-\rho g h\right)$, where $\Delta p$ is a difference between before and after valve pressures; $p_{G}$ is gas tank pressure; $\rho g h$ is liquid hydrestatic pressure; $k$ is valve coefficient.

For the cases presented in Fig. 3, if gas injected volume is small enough $\left(V_{G} \leq 0.09\right.$ $\mathrm{m}^{3}$ ), larger opened time of gas lift valve, bigger liquid volume reaches the surface. If the gas injected volume is bigger than this limit $\left(V_{G}>0.09 \mathrm{~m}^{3}\right)$, the effect will be opposite and process efficiency will reduce when gas injected into lift conduit volume increases. It should be noticed that the gas injected volume can be managed by both valve opened time and pressure in gas reservation tank. The sensor signal analyses also confirmed this remark.
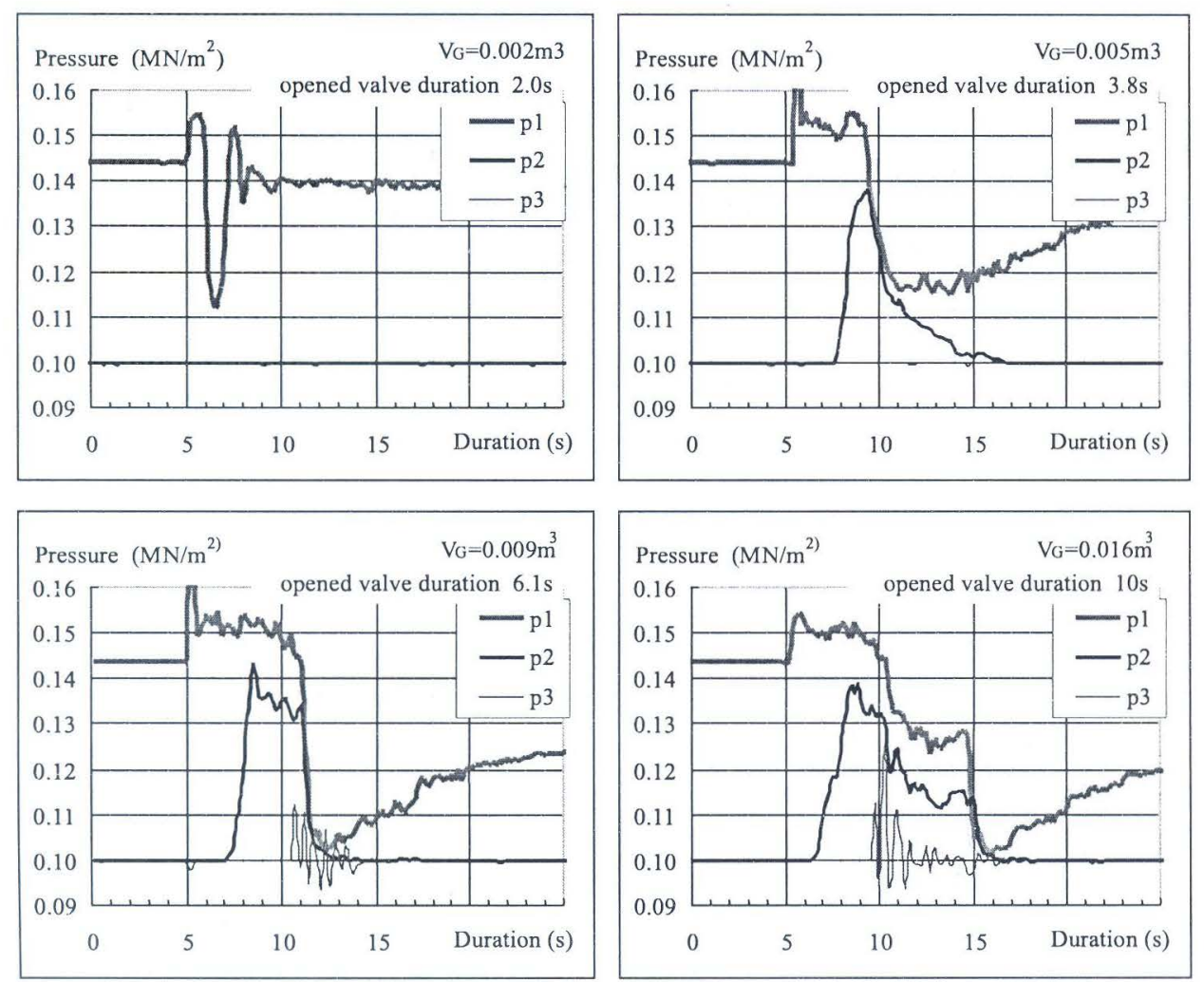

Fig. 3. Pressure curves for 3 points $p_{1}, p_{2}$ and $p_{3}$ along the experimental lift conduit (spindle oil; $d=24 \mathrm{~mm} ; \varphi=0^{\circ} ; H=16 \mathrm{~m} ; p_{G}=0.2 \mathrm{MN} / \mathrm{m}^{2}$ )

In Fig. 4 the dependence of liquid received in surface volume on gas injected into lift conduit volume for different initial liquid height in conduits is presented. It should be noticed that the curves begin not from zero, because if the gas injected into conduit volume is too small, the liquid can not be lifted to surface and liquid received volume is zero. From Fig. 4 it can be seen that received liquid volume in surface will increase if the gas injected volume increases. The increase of initial, liquid height in lift conduit leads into also increase of received liquid volume in the surface.

In Fig. 5 the gas/liquid (oil) ratio $\mathrm{GOR}=V_{G} / V_{L}$ is presented in dependence on the gas injected into conduit volume. From Fig. 5 it can be seen that the dependence of GOR 
on gas injected volume $V_{G}$ is quite different in comparison with the dependence of the received liquid volume $V_{L}$ on $V_{G}$ presented in Fig. 4. Initially GOR is very high. If the gas injected volume is too small, GOR will be infinity (because $V_{L}=0$ ). After that this value decreases strongly and reaches the minimum point. From this point, the gas/liquid ratio will increase again, if the gas injected volume increases.

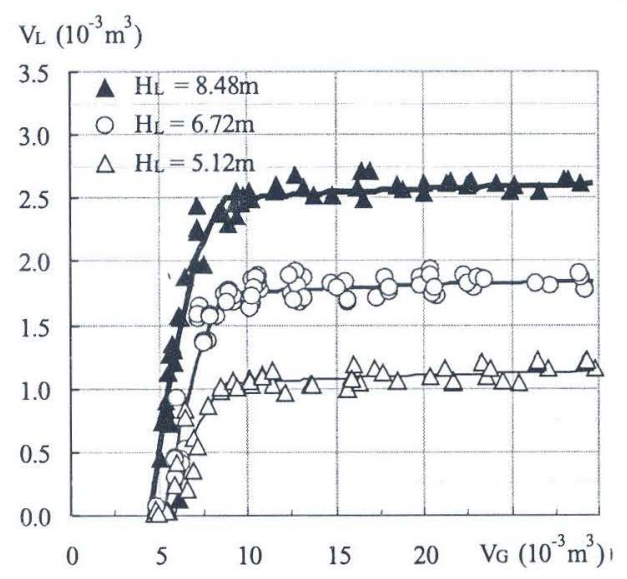

Fig. 4. Liquid volume $V_{L}$ received in surface in dependence on gas injected volume $V_{G}$ (water; $d=24 \mathrm{~mm} ; H=16 \mathrm{~m} ; \varphi=0^{\circ} ; p_{G}=0.2 \div 0.3$ $\left.\mathrm{MN} / \mathrm{m}^{2}\right)$

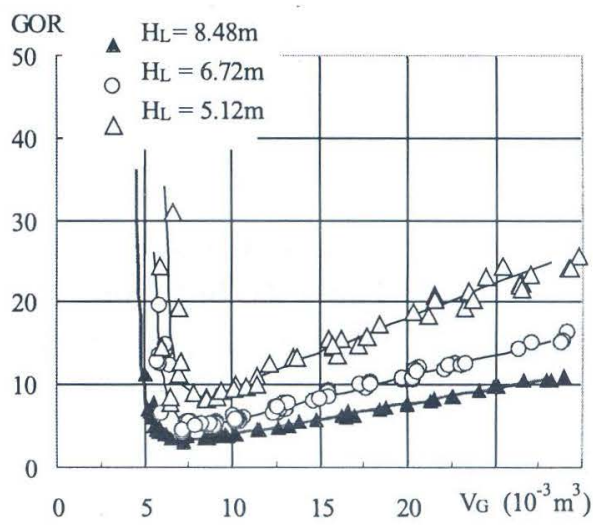

Fig. 5. Gas/liquid ratio $\mathrm{GOR}=V_{G} / V_{L}$ in dependence on gas volume injected into lift conduit $V_{G}$ (water; $d=24 \mathrm{~mm} ; H=16 \mathrm{~m} ; \varphi=0^{\circ}$; $\left.p_{G}=0.2 \div 0.3 \mathrm{MN} / \mathrm{m}^{2}\right)$

From Fig. 5 it can be seen also that the minimum value of gas/liquid ratio will decrease, if the liquid initial height in lift conduit increases. The gas/liquid ratio GOR represents the gas volume required to lift one volume unit of liquid to the surface, so this value decrease means that the gas expense for lift of one liquid volume unit decreases and the process becomes more efficient.

The received results presented in Fig. 5 show once more again the important role of the gas injected into lift conduit volume. The development of the gas bubble in the lift conduit determines the gas lift process and the received liquid volume in the surface. If the gas injected volume is too small, received liquid volume will be zero.

The experimental data show that if the gas injected into lift conduit volume $V_{G}$ is not too small, the gas/liquid ratio will be minimum when the gas injected volume determined as follow:

$$
V_{G \min }=\frac{(1-k)(p+\rho g h)+k p_{G}}{p_{n}}\left(V_{T}-V_{\text {L.remain }}\right),
$$

where $p$ is pressure in the out-end of the lift conduit; $p_{n}$ is pressure in standard condition $\left(p_{n}=0.1013 \mathrm{MN} / \mathrm{m}^{2}\right) ; \rho g h$ is hydrostatic pressure of liquid in lift conduit; $k$ is a coefficient ( $k$ depends on valve structure, and in the presented in the paper conditions $k=0.12$ ); $V_{T}$ is the full volume of lift conduit; $V_{\text {L.remain }}$ is the liquid volume remained in conduit after a cycle of the gas lift completion.

In accordance to Table 1 , the increase of gas tank pressure leads to the decrease of liquid volume remained in the lift conduit. It may have the relationship with the liquid film thickness along the lift conduit and fall back liquid volume during the gas lift process. 
Table 1. Experimental results $V_{L . r e m a i n} / V_{T}$ (in \%)

\begin{tabular}{|c|c|c|c|c|c|c|}
\hline & \multirow{2}{*}{$\mathrm{p}_{G}\left(\mathrm{MN} / \mathrm{m}^{2}\right)$} & \multicolumn{3}{|c|}{$\varphi=0^{\circ}$} & \multicolumn{2}{c|}{$\mathrm{d}=24 \mathrm{~mm}$} \\
\cline { 3 - 8 } & & \multicolumn{2}{|c|}{$\mathrm{d}(\mathrm{mm})$} & \multicolumn{2}{c|}{$\varphi$} \\
\cline { 3 - 8 } & & 18 & 24 & 31 & $7^{\circ}$ & $14^{\circ}$ \\
\hline Water -air & $0.2 \div 0.25$ & 19 & 19 & 19 & - & - \\
\hline \multirow{2}{*}{ Spindle oil-air } & 0.2 & 27 & 26 & 30 & 27 & 27 \\
\cline { 2 - 8 } & 0.25 & 26 & 25 & 28 & 25 & 26.5 \\
\hline
\end{tabular}

From Table 1 it can be seen also that for the water-air system the liquid volume remained in the lift conduit after the gas lift process completion is smaller than for the spindle oil-air system.

Despite that the density of spindle oil is smaller than the similar characteristic of water (see, for example, Table 2), but from Table 1 we can see that the liquid volume remained in lift conduit in the case of spindle oil-air system is bigger than in the case of water-air system. It means that besides density the viscosity plays also important role in the gas lift process. From Table 2 it can be seen that the viscosity of spindle oil is significant higher (about 5 times) than the viscosity of water. The liquid volume remained in lift conduit will increases if liquid viscosity increases.

Table 2. Medium characteristics in laboratory and real conditions

\begin{tabular}{|c|c|c|}
\hline Characteristics & $\begin{array}{l}\text { Laboratory } \\
\text { conditions }\left(25 \div 27^{\circ} \mathrm{C}\right)\end{array}$ & $\begin{array}{l}\text { Real conditions } \\
\left(30 \div 120^{\circ} \mathrm{C}\right)\end{array}$ \\
\hline $\mathrm{d}(\mathrm{mm})$ & 18 & 62 \\
\hline $\mathrm{H}(\mathrm{m})$ & 16 & $\sim \quad 3000$ \\
\hline $\begin{array}{l}\rho_{L} \\
\left(\mathrm{~kg} / \mathrm{m}^{3}\right)\end{array}$ & $\begin{array}{l}998 \text { (water) } \\
860 \text { (spindle oil) }\end{array}$ & $\begin{array}{l}550 \div 860 \\
\text { (crude oil) }\end{array}$ \\
\hline $\begin{array}{l}\rho_{G} \\
\left(\mathrm{~kg} / \mathrm{m}^{3}\right)\end{array}$ & $\begin{array}{l}1.19 \\
\text { (air) }\end{array}$ & $\begin{array}{l}1.23 \\
\text { (natural gas) }\end{array}$ \\
\hline $\begin{array}{l}\mu_{L} \\
\left(10^{-3} \mathrm{~N} . \mathrm{S} / \mathrm{m}^{2}\right)\end{array}$ & $\begin{array}{l}0.9 \text { (water) } \\
4.5 \text { (spindle oil) }\end{array}$ & $\begin{array}{l}0.44\left(137^{\circ} \mathrm{C}\right) \\
4.61\left(50^{\circ} \mathrm{C}\right)\end{array}$ \\
\hline$\mu_{G}\left(10^{-3} \mathrm{~N} \cdot \mathrm{S} / \mathrm{m}^{2}\right)$ & $\begin{array}{l}1.810^{-3} \\
\text { (air) }\end{array}$ & $\begin{array}{l}1.910^{-2} \\
\text { (natural gas) }\end{array}$ \\
\hline $\begin{array}{l}\sigma_{L} \\
(\mathrm{~N} / \mathrm{m})\end{array}$ & $\begin{array}{l}7.210^{-2} \\
\text { (water-air) } \\
4.510^{-2} \\
\text { (spindle oil-air) }\end{array}$ & $\begin{array}{l}3.210^{-2} \\
\text { (crude oil -natural gas) }\end{array}$ \\
\hline $\mathrm{g}\left(\mathrm{m} / \mathrm{s}^{2}\right)$ & 10 & 10 \\
\hline $\mathrm{V}(\mathrm{m} / \mathrm{s})$ & $1 \div 6$ & $2 \div 3$ \\
\hline
\end{tabular}

The received experimental data also show the significant influence of the conduit inner diameter d on the process and the liquid volume received in surface (Fig. 6).

However if we estimate the influence of the conduit inner diameter on the relationship between received liquid volume and gas injected volume using dimensionless unit such as $V_{G} / V_{T}$ (Fig. 7), we can see that for the conduits used in presented in this paper experiments the relation between these two quantities are the same or the curves coincide. It should be 
noticed that in reality the inner lift conduit diameter may have more significant influence on the gas lift efficiency through Phase 4 and oil accumulated time.

Besides the lift conduit inner diameter, the conduit configuration also has a significant influence on the gas lift process. In Fig. 8 the influence of reservation chamber installed in the bottom part of conduit and diameter expansion in the out end of conduit on the gas lift efficiency is presented.

From Fig. 8 it can be seen that besides the liquid accumulation time economy, the reservation chamber can significantly increase the efficiency of gas lift process. The received liquid volume can be raised more than one and haft time in comparison with the conduit without chamber. In opposite, from Fig. 8 it can be also seen that diameter expansion of lift conduit at the out end (two step conduit) leads to reduction of the gas lift process efficiency.

In reality the oil production wells are not strictly vertical, but normally they incline with some angles $\varphi$. To investigate the influence of well inclination on the gas lift efficiency the experiments with inclined conduits are carried out. The parameter measurement and procedures are the same with the vertical conduit cases. From the received results (see Fig. 9) it can be seen that the qualitative relationship between the gas/liquid ratio GOR and gas injected volume is changed not much and stayed the same as presented in Fig. 5 for vertical cases, but quantitative relationships are different and the received liquid volumes will decrease when inclination angles increase.

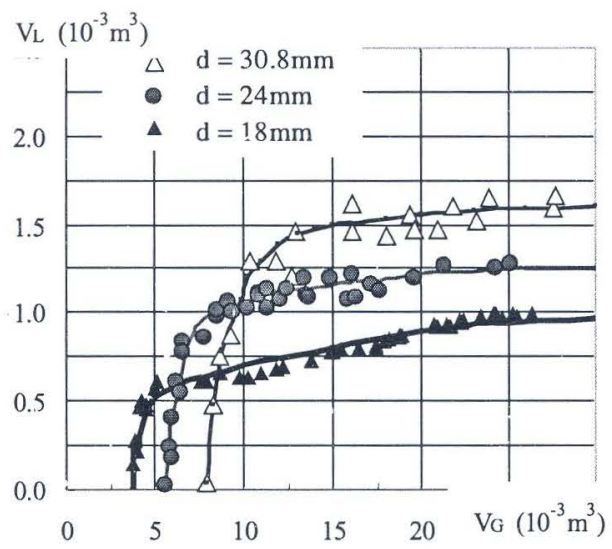

Fig. 6. Influence of conduit inner diameter $d$ (water; $H=16 \mathrm{~m}: \varphi=0^{\circ} ; p_{G}=0.2 \div 0.3$ $\mathrm{MN} / \mathrm{m}^{2}$

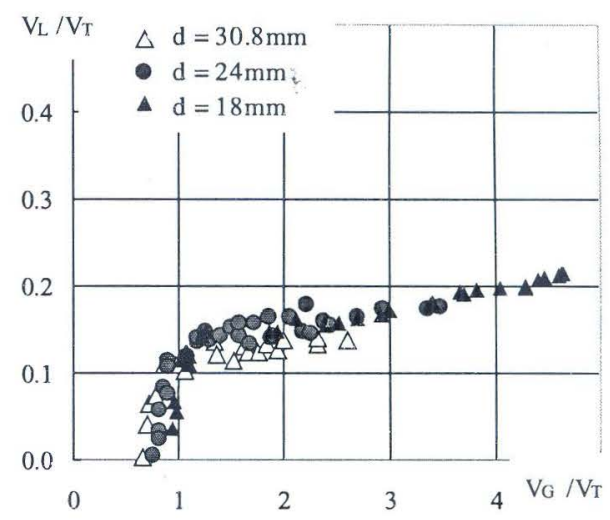

Fig. 7. Influence of conduit inner diameter $d$ in dimensionless unit $V_{G} / V_{T}$ (water; $H=16 \mathrm{~m}$; $\left.\varphi=0^{\circ} ; p_{G}=0.2 \div 0.3 \mathrm{MN} / \mathrm{m}^{2}\right)$

The influence of medium properties on the considered process is studied through the experiments implemented for two different liquid-gas systems, namely, for water-air spindle oil No.10 - air (Fig. 10). With the same other parameters such as conduit diameter, initial liquid height, gas injected pressure, etc., the received liquid volumes for water-air case are always higher than similar quantity for spindle oil -air case. As already mentioned before, the main medium parameters in these cases are the liquid density, surface tension and viscosity. From Table 2 it can be seen that the density of water is bigger than spindle oil density. This means that to lift water is more difficult. But the water viscosity is significant 


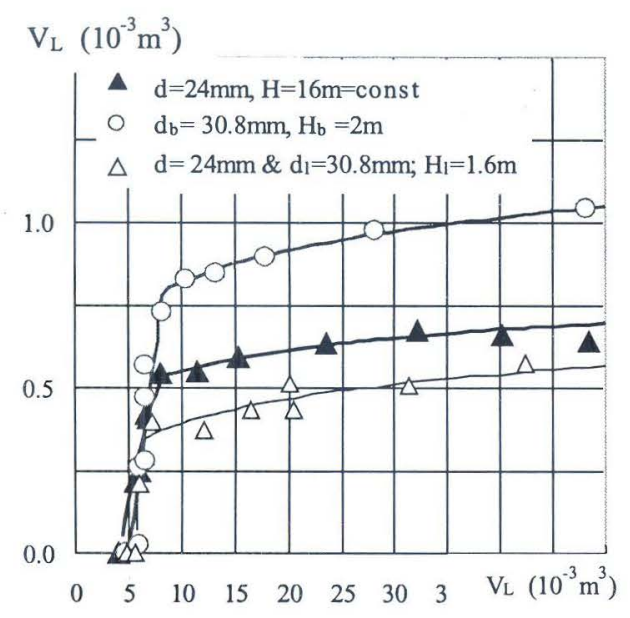

Fig. 8. Influence of reservation chamber $(\mathrm{O})$ and conduit diameter expansion $(\delta)$ on gas lift efficiency (spindle oil; $\varphi=0^{\circ} ; p_{G}=0.2$ $\mathrm{MN} / \mathrm{m}^{2} ; H_{L}=5.12 \mathrm{~m}$ )

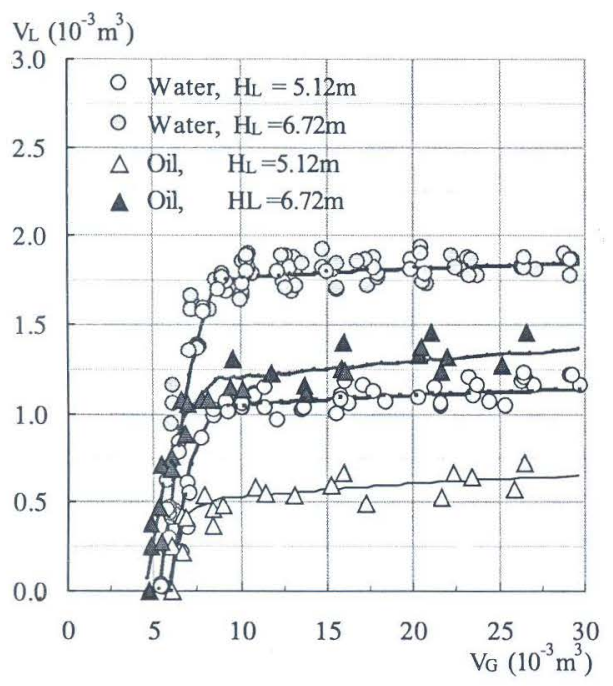

Fig. 10. Influence of medium properties: Experimental data $V_{L}$ for spindle oil-air and water-air $\left(d=24 \mathrm{~mm} ; \varphi=0^{\circ} ; p_{G}=0.2 \div 0.3\right.$ $\mathrm{MN} / \mathrm{m}^{2}$ )

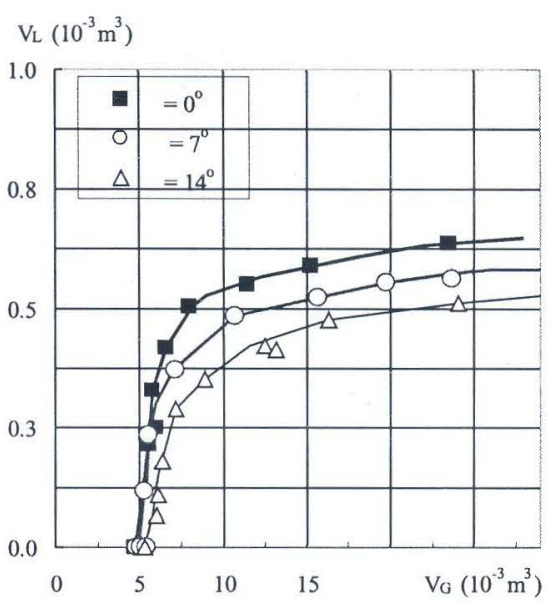

Fig. 9. Influence of the inclination angles $\varphi$ on the received liquid volume $V_{L}$ in dependence on $V_{G}$ (spindle oil; $H=16 \mathrm{~m} ; p_{G}=0.2 \mathrm{MN} / \mathrm{m}^{2}$; $\left.H_{L}=5.12 \mathrm{~m}\right)$

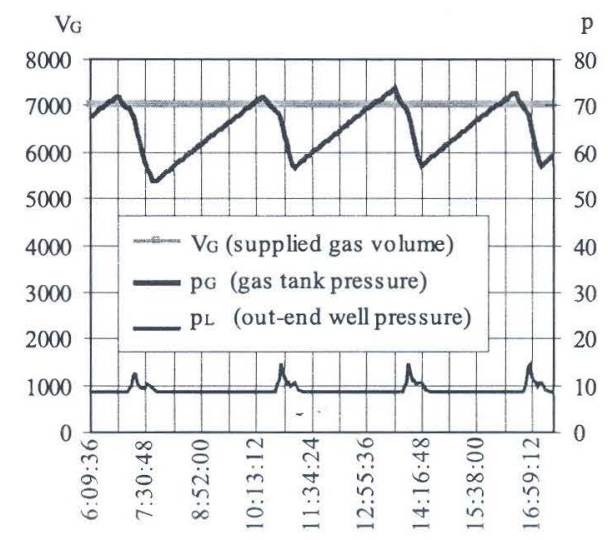

Fig. 11. Pressure and gas injected volume curves for real oil well using periodical gas lift technology (crude oil; $H=3395 \mathrm{~m} ; V_{L}=4.6$ ton/day)

smaller than the spindle oil viscosity. This factor leads to increasing lift process efficiency. And as results shown in Fig. 10, in total the water lift by gas is easier than spindle oil lift by the same way.

In Fig. 11 the pressure curves ( $p_{G}$ is gas tank (annular) pressure and $p_{L}$ is liquid pressure at the out end of oil well) and supplied gas flow $V_{G}\left(\mathrm{~m}^{3} /\right.$ day) of gas for real oil 
Table 3. Main dimensionless similarity criteria

\begin{tabular}{|l|l|l|l|}
\hline Criteria & Definition & $\begin{array}{l}\text { Laboratory condi- } \\
\text { tions }\end{array}$ & Real conditions \\
\hline $\mathrm{H}_{C}$ & $\mathrm{H} / \mathrm{d}$ & $10^{3}$ & $50.10^{3}$ \\
\hline $\mathrm{Fr}$ & $\mathrm{V}^{2} / \mathrm{gd}$ & 11 & 14.5 \\
\hline $\mathrm{We}$ & $\rho \mathrm{d} \mathrm{V} / \sigma$ & $10^{3} \div 10^{4}$ & $9.10^{3}$ \\
\hline $\operatorname{Re}_{L}$ & $\rho_{L} \mathrm{~d} \mathrm{~V} L / \mu_{L}$ & $4.10^{3} \div 5.10^{4}$ & $26.10^{3}$ \\
\hline $\operatorname{Re}_{G}$ & $\rho_{G} \mathrm{~d} \mathrm{~V} G / \mu_{G}$ & 60 & 170 \\
\hline
\end{tabular}

well using periodical gas lift technology are presented in dependence on time. We can see that for one cycle, the curves are very similar with what was presented in previous part of this paper. The base of using laboratory measurement for analysis of real situation is the dimensionless similarity criteria coinciding.

In Table 3 the main dimensionless similarity criteria such as calibrated conduit length $H_{C}$, Frud number Fr, Weber number We, Reynolds number for liquid $\mathrm{Re}_{L}$ and for gas $\operatorname{Re}_{G}$ for laboratory (spindle oil No.10, water and air) and for real conditions (crude oil and natural gas) are presented. From Table 3 it can be seen that exclusive calibrated length $L_{C}$, which can not be satisfied properly in the laboratory because of big value of real oil well length, the other dimensionless similarity criteria are closed each other for laboratory and real conditions.

\section{CONCLUSIONS}

The periodical gas lift experiments for two medium systems, namely, water-air and spindle oil No.10 -air are implemented to study the influence of main characteristics on considered process. The data set are obtained and analysed. Besides the gas injection volume, the medium characteristics, tubing geometry and configuration are main factors which influence on the considered process efficiency. Using enlargement tubing as liquid reservation chamber at the bottom part of lift tube leads to higher efficiency. In opposite, the expansion of tube out end leads to efficiency reduction effect. For determined initial liquid accumulation height the optimal regime with minimum gas/liquid ratio exists. The coinciding of the main dimensionless similarity criteria for laboratory and real conditions of oil production are basic for using the laboratory results and conclusion to analyse the similar situation in reality.

The paper is completed with partly financial support from Vietnam National Fund for Basic Investigation in Natural Science.

\section{REFERENCES}

1. J. Y. Brill, T. C. Doerr and K. E. Brown, An Analytical Description of Liquid Slug Flow in Small-Diameter Vertical Conduits, J. Petr. Tech. 19 (1967) 419-32.

2. R. Collins et al., The Motion of Large Gas Bubbles Rising Through Liquid Flowing in a Tube, J. Fluid Mech. 89 (1978) 497-514.

3. Duong Ngoc Hai, Nguyen Duy Thien, Ha Cong Tu, Model Study of the Vertical Flows of Intermittent Gas Lifting, Proc. of The $5^{\text {th }}$ International Conference on Multiphase Flow ICMF'04, Yokohama, Japan, May 30 - June 4, 2004. 
4. J. Fabre et al., Intermittent Gas-Liquid Flow Modeling in Horizontal or Weekly Inclined Pipes, Proc. of The Int. Conf. on The Physical Modeling of Multiphase Flow, Coventry, UK, 1983.

5. G. F. Hewitt, et al., Transition in Film Flow in a Vertical Tube, Proc. of Symp. on Two Phase Flow, Exeter, UK, B401-430, 1965.

6. G. A. Hughmark, Film Thickness Entrainment and Pressure Drop in Upward Annular and Dispersed Flow, AIChE. J. 19 (5) (1973) 1062-64.

7. A. B. Neely, J. W. Montgomery and J. V. Vogel, A Field Test and Analytical Study of Liquid Loss in Intermittent Gas Lift, Soc. Petr. Eng. J. 14 (1974) 502-12.

8. R. I. Nigmatulin, Dynamics of Multiphase Media, Hemisphere Pub. Co., USA, 1991.

9. G. S. Odair, N. B. Sergio, Francisco J.S.A., Study of the dynamics, optimization and selection of intermittent gas-lift methods - a comprehensive model, JPSE 32 (2001) 231-317.

10. Z. Schmidt, et al., Hydrodynamic Model for Intermittent Gas Lifting of Viscous Oil, J. Pet. Tech. 36 (1984) 475-85.

11. Y. Taitel, D. Barnea, A. E. Dukler, Modelling Flow Pattern Transitions for Steady Upward Gas-Liquid Flow in Vertical Tubes, Int. J. Multiphase Flow 18 (1) (1982) 1-10.

12. G. B. Wallis, One Dimensional Two-Phase Flow, McGraw-Hill, 1969.

Received June 21, 2007

\section{KẾT QUẢ THỰC NGHIỆM VỀ QUÁ TRİNH NÂNG CHẤT LỎNG DÙNG KHÍ}

Bài báo trình bày một số kết quả thực nghiệm nghiên cứu quá trình nâng chất lỏng trong ống đứng dùng khí (gaslift) gián đoạn - một công nghệ được áp dụng trong khai thác dầu thô. Thiết bị nghiên cứu thực nghiệm gồm nhiều ống đứng (thẳng, nghiêng, nhiều loại đường kính khác nhau, ...), trên ống có lắp các đầu đo áp suất, ngoài ra còn có các đầu đo phụ khác. Dựa trên các tín hiệu đo, có thể xác định tốc độ dòng chảy, sự dao động áp lực và thể tích khí, thể tích chất lỏng trong ống, vào/ra khỏi đường ống. Thực nghiệm nhằm nghiên cứu một số quy luật về quá trình, dòng chảy, ảnh hưởng của kích thước, hình dạng ống, thể tích khí nén, khối lượng chất lỏng ban đầu, tính chất vật lý của chất lỏng ... đến hiệu quả áp dụng công nghệ nâng đẩy chất lỏng bằng công nghệ dùng khí gián đoạn, ví dụ, khi nén vào đáy giếng khai thác dầu thô,..... 